\title{
Association of interleukin-10 promoter genetic variants with T-cell and B-cell activation in HIV-1 infection
}

\author{
D Naicker ${ }^{1 *}$, B Julg${ }^{2}$, C McClurg ${ }^{2}$, M Ghebremichael ${ }^{2}$, F Porichis ${ }^{2}$, J Zupkosky² ${ }^{2}$ M Jaggernath ${ }^{1}$, M Mokgoro ${ }^{1}$, \\ P Goulder ${ }^{3}$, B Walker ${ }^{2}$, D Kaufmann², T Ndung'u'
}

From AIDS Vaccine 2012

Boston, MA, USA. 9-12 September 2012

\section{Background}

Interleukin-10 (IL-10) is a potent immunoregulatory cytokine, with promoter polymorphisms that have previously been associated with HIV-1 susceptibility and pathogenesis. Association of IL-10 SNPs with markers of CD4, CD8 and B cell activation has not previously been investigated.

\section{Methods}

Two IL-10 polymorphisms were genotyped by TaqMan allelic discrimination and markers of activation of CD4, CD8 and B cells were measured in 63 individuals using flow cytometry. The following monoclonal antibody combinations were used: anti-CD3 Pac-blue, anti-CD38 PE-Cy7, anti-HLA-DR ACP-Cy7, anti-CD95 PE, antiCD19 Alexa-700, anti-IgG PE-Cy5, anti-PD-1 APC, antiKi67 FITC, anti-CD4 Qdot605 and anti-CD8 Qdot655.

\section{Results}

Previous studies on this cohort showed a significant association between -1082GG and higher median IL-10 expression, compared to the $-1082 \mathrm{AA} / \mathrm{AG}(\mathrm{p}=0.0006)$. The -592AA and -1082AA (both previously shown to be associated with low-IL-10 production) had significantly higher median expression of HLA-DR on CD4 and CD8 cells respectively, compared to the other genotypes $(-592 A A$ vs. $-592 C A \mathrm{p}=0.005,-592 A A$ vs. $-592 C \mathrm{C}=$ 0.03 and $-1082 \mathrm{AA}$ vs. $-1082 \mathrm{AG} \mathrm{p}=0.02$ ). The $-592 \mathrm{AA}$ genotype also had a higher median expression of CD95 and PD- 1 on CD4 cells (-592AA vs. $-592 \mathrm{CA} \mathrm{p}=0.0227$, $-592 \mathrm{AA}$ vs. $-592 \mathrm{CC} \mathrm{p}=0.0270$ and $-592 \mathrm{AA}$ vs. $-592 \mathrm{CA}$ $\mathrm{p}=0.01$ respectively). The $-592 \mathrm{CC}$ and $-1082 \mathrm{GG}$ genotypes associated with higher median expression of IgG on the surface of $B$ cells $(-592 \mathrm{CC}$ vs. $-592 \mathrm{AA} \mathrm{p}=0.0207$ and $-1082 \mathrm{GG}$ vs. $-1082 \mathrm{AG} p=0.0392,-1082 \mathrm{GG}$ vs. $-1082 \mathrm{AA}$ $\mathrm{p}=0.0051)$.

\section{Conclusion}

These data suggest that IL-10 polymorphisms that affect cytokine production and HIV pathogenesis may affect markers of immune activation and exhaustion in response to antigen, and suggest a beneficial role for IL-10 in chronic HIV infection. Further studies on association between IL-10 and the quality and magnitude of immune responses in HIV infection are needed.

\section{Author details}

${ }^{1}$ HIV Pathogenesis Programme, Durban, South Africa. ${ }^{2}$ Ragon Institute of MGH, MIT and Harvard, Boston, MA, USA. ${ }^{3}$ University of Oxford, Department of Paediatrics, UK.

Published: 13 September 2012

doi:10.1186/1742-4690-9-S2-P168

Cite this article as: Naicker et al.: Association of interleukin-10 promoter genetic variants with T-cell and B-cell activation in HIV-1 infection. Retrovirology 2012 9(Suppl 2):P168.

${ }^{1}$ HIV Pathogenesis Programme, Durban, South Africa

Full list of author information is available at the end of the article

(c) 2012 Naicker et al; licensee BioMed Central Ltd. This is an Open Access article distributed under the terms of the Creative Commons Attribution License (http://creativecommons.org/licenses/by/2.0), which permits unrestricted use, distribution, and reproduction in any medium, provided the original work is properly cited. 